\title{
LXXIV. On galvanic circuits composed of two fluids, and of two metals not in contact
}

\section{Professor J.C. Poggendorff}

To cite this article: Professor J.C. Poggendorff (1840) LXXIV. On galvanic circuits composed of two fluids, and of two metals not in contact, Philosophical Magazine Series 3, 16:105, 485-498, DOI: $10.1080 / 14786444008650076$

To link to this article: http://dx.doi.org/10.1080/14786444008650076

册 Published online: 01 Jun 2009.

Submit your article to this journal

Џ Article views: 2

Q View related articles $\square$ 
LXXIV. On Galvanic Circuits composed of two Fluids, and of two Metals not in contact. By Professor J. C. PoggenDORFF.*

TN support of the so-called Chemical Theory of galvanism, or rather of that view which places the source of voltaic electricity solely in the chemical affinity of the positive metal of the circuit, viz. the zinc, for the electro-negative constituent of the fluid, Mr. Faraday has of late brought forward in an especial manner the three following arguments :-

1. The production of a spark on completing the junction of a simple circuit.

2. The electrolytic law.

3. The preponderance of a circuit of zinc, platina, and sulphuric acid, over one formed of the same metals and a solution of the iodide of potassium.

With respect to the first point, the production of a spark on making the connexion between a single pair of plates, Faraday, in the Eighth Series of his Experimental Researches, lays much stress upon it, and for this reason;-because it must have passed before the metals could have come into contact, and thus not only proves its origin from pure chemical forces, but also the superfluousness of metallic contact for exciting voltaic electricity $\dagger$; in the further progress of his labours the English philosopher seems, however, to have some doubt as to the reality of a spark on junction; at least he expresses himself in his ninth series in a manner which induces the belief that he considers this spark to be a heating and ignition of the mercury employed in the experiment at or after the moment of junctionf.

Moreover, Professor Jacobi, in an experiment performed for the very purpose of solving this doubt, in which the wire of junction of a simple, very powerful zinc-platina circuit was interrupted by a layer of air only 0.00005 inch, was not able to perceive the least sign of the passing of a spark at the place of disjunction §. And recently Professor Draper, in New York, could not even observe the spark in a perfect vacuum before direct contact between the mercury and the wire which formed the arc of junction of a simple circuit\|.

* From Poggendorff's Annalen, vol. xlix. January, 1840 : translated by Mr. W. Francis.

$\dagger$ Experimental Researches, Ser, viii. \$. 915.

† Ibid. §. 1074 .

London and Edinburgh Philosophical Magazine, vol, xiii. p. 401.

\|I Ibid. vol, xv. p. 349. 
It can no longer, therefore, be a question whether there is a true spark on junction without metallic contact; moreover, other good reasons render very improbable the existence of the high tension requisite in the still open simple circuit*.

The electrolytic law is otherwise circumstanced. The correctness of this important law, with which Faraday has enriched the science of electricity, can be subject to no doubt; but many well-founded objections may be raised against its interpretation in favour of the chemical theory. The law consists in the fact that the quantities of the bodies decomposed in the single cells of the voltaic battery are in proportion to the chemical equivalents. It proves that the passage of like quantities of electricity is necessary for the decomposition of equivalent masses, but nothing more. It takes no part in the question respecting the origin of galvanic electricity. It is equally correct, whether the voltaic current originate from the contact of the metals, or from the chemical action on the zinc, or from any other causet.

A proof in favour of the one or the other origin might perhaps be drawn from it, were it exclusively peculiar to the voltaic current, which would at the same time establish quite an essential distinction between voltaic electricity and magnetic, thermal, frictional, and animal electricity. But if, on the other hand, it is no peculiarity of the voltaic electricity, if it is rather

* [At the time when the sheets of the German original were sent to press, Prof. Poggendorff had not seen the collective edition of the Experimental Researches, in the preface to which Mr. Faraday acknowledges himself to have been in error with respect to the production of the spark without contact.-W. F.]

$\dagger$ The error with respect to using this law as an argument has originated from presupposing what first ought to have been proved by it, that the excitation of the electricity was effected by the solution of the zinc; while in reality, this solution, when amalgamated zine and dilute sulphuric acid are employed, is solely the effect, the product of the electric current, and, when common zinc is used, arises partly from this current and in part from a pure chemical process entirely foreign to the circuit. It has happened with this law as with the wellknown fact that in general the easily oxidable metals are the more positive. A connexion between oxidability and positiveness is accordingly evident, but which of these is causal, this or that, remains totally undecided. That it is, nevertheless, still continued to be interpreted in favour of the chemical theory, is the less justifiable, as several cases are known (and may every moment be increased by new ones) where the negative metal, notwithstanding that it is actually much more powerfully acted upon by acids than the positive one, still remains negative towards this. We need only call to mind the old experiment of Berzelius (Gilb. Annalen, vol. xxxv. p. 27), which, it is true, De la Rive conceives he has refuted, but which has long since been satisfactorily confirmed by Ohm. Moreover, the fact observed by Ritter, Davy, and many others, and which I have recently confirmed, that amalgamated zinc, notwithstanding it is little or not at all attacked by dilute acids, is in these considerably positive towards the so easily soluble unamalgamated zinc, deserves to be rescued from oblivion. 
a property of all electric currents to decompose on their passage through a series of different fluids equivalent quantities of each, then $\grave{a}$ priori, every consequent conclusion from the law with respect to the origin of voltaic electricity is impossible. That the latter is then actually the case, that in fact the electrolytic law is common to all electric currents, that consequently the identity of electricities of various origin (manifoldly proved by Faraday himself in other respects) is established with reference to this law also, the simple experiment, published by me last year, on the simultaneous decomposition of two portions of water by the same magneto-electric current, can leave not the least room for doubt*.

Of the arguments advanced in favour of the chemical theory, there is now left in force for the present only the third.

The experiment upon which this is mainly founded consists in the fact, that two strips, one of zinc and the other of platina, are separated at their extremities, on the one side by sulphuric acid, on the other by a solution of the iodide of potassium. An electric current then occurs in a direction which indicates the preponderance of the sulphuric acid circuit over that of the iodide of potassium. The iodide of potassium, which, in case the two metallic slips are in direct contact at their other end, is decomposed in such manner, that its electro-negative constituent, the iodine, passes over to the zinc, gives it to the platina as soon as metallic contact is suspended at those ends and sulphuric acid inserted there.

Faraday places this experiment at the head of his researches on the origin of voltaic electricity. He regards it, as it were, as a scale for weighing two chemical affinities, that of the oxygen and that of the iodine for the zinc. Both endeavour, according to him, to excite an electric current; but that of the oxygen being the strongest, sets more electricity in movement than that of the iodine; the latter is therefore overpowered, and a current thus originates in the direction of the affinity of the oxygen, which, at the same time, since the two metals do not touch, affords another proof of the non-necessity of metallic contact to excite voltaic electricity.

The experiment is so remarkable, and the explanation given has in appearance so much plausibility, that it is not to be wondered at if the supporters of the chemical theory of galvanism have regarded it as a main prop of their opinion. Upon the defenders of the contact theory it made, however, but little impression, probably from their believing that no

* Poggendorff's Annalen, vol. xliv. p. 642. 
regard need be had to an isolated fact speaking apparently in favour of the chemical theory, considering the numerous objections which may be urged against it.

In general they may have contented themselves with this otherwise perfectly correct position, that one metal, as soon as it is in contact with two fluids, can no longer be regarded as a single metal; so, for instance, that in Faraday's experiment that end of the zinc-bar which touched the sulphuric acid would be positive towards that which was moistened by the solution of the iodide of potassium. This at least is the opinion which Pfaff advances in his Revision der Lehre vom Galvano-Voltaismus*. Pfaff is also, as far as I am aware, the only philosopher on the continent who has hitherto publicly discussed this experiment, without, however, performing more than a mere repetition of it experimentally.

From the great importance which, be it with justice or not, is assigned by the majority of the philosophers of the present day to the decision of the question respecting the origin of voltaic electricity, a more accurate examination of the process in the Faradayan circuit appeared to me not to be without value, and I therefore undertook the experiments, the results of which will be enumerated in the following pages as briefly and clearly as possible.

Galvanic circuits of two fluids and two metals not in contact may truly, as is readily conceived, be constructed without number. The English philosopher has examined a few, and these few always composed only of zinc and platina with various fluids. With this slight number of cases he always obtained results favourable to his view.

It appeared in the first instance to me to depend on this point : let it be seen whether among the great number of possible cases there may not be some which could not be brought under this view. If this question were affirmed by experiment, another demand would arise; namely, to subject Faraday's explanation even for the apparently favourable cases to a more rigorous examination.

Above all, I considered a greater change with the metals to be necessary, as, from long-known experience in other cases, it seemed to me highly improbable that the negative metal of the

* P. 81. It stands there, it is true, quite reversed, that the platina was positive in the acid, and the zine negative; but the connexion shows that this is only founded in a permutation or typographical error. In this memoir that metal is always termed positive which acts towards a second as zinc to copper in the common circuit. 
circuit should act so passive a part as is assigned to it according to the theory at present prevailing in England.

I therefore made choice of the six metals: platina, silver, copper, tin, iron, and zinc, (common as well as distilled and amalgamated). In some cases I examined all the combinations which might be formed into pairs from these elements ; in most cases, however, I was satisfied with circuits containing zinc, iron, or tin, as the positive element, since the three noble metals combined inter se give rise only to very slight effects. All the metals were as pure as they could possibly be obtained, and formed plates of nearly equal size, viz. somewhat about 3.5 inch in length, and 1 inch in breadth.

The fluids employed were: water, dilute sulphuric acid (acid of 1.827 spec. gr. diluted with 9 times its volume of water), dilute nitric acid (acid of $1.321 \mathrm{sp}$. gr. with 6 times its vol. of water), dilute hydrochloric acid (acid of 1.138 sp. gr. with 6 times its vol. of water), saturated solution of chlorine, liquid caustic ammonia (of 0.97 spec. gr. diluted with 4 times its vol. of water), and solutions of caustic potassa (1 part in weight to 4 parts in weight of water), carbonate of soda ( 1 in 3 water), sulphate of magnesia ( 1 to 3 water), borax (saturated), sulphate of zinc ( 1 to 4 water), salt (saturated), sal-ammoniac (saturated), and iodide of potassium (1 part in weight to 4 in weight of water). Distilled water was employed for the solutions; but where the water alone was tested, spring water was generally made use of, as it conducts better than distilled water, and does not sensibly differ in its electromotive action. All the above substances were as pure as possible; thus the sulphuric acid was free from nitric acid, the hydrochloric acid from chlorine.

The mode of performing the experiments was as follows:

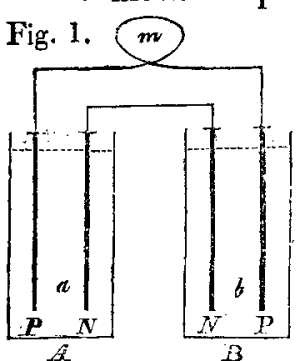
into two small glass vessels $(A, B) \mathrm{I}$ poured two of the above fluids $(a, b)$ to the height of 2.5 inches, placed in each a heterogeneous pair of plates $(P, N)$, and connected the plates of like nature by copper wires, of which one was the wire of the multiplier $(m)$, whose needle had to indicate by its deflection the presence, the direction, and also comparatively the force of the electric current.

Two arrangements, which I will here describe more fully, from their great usefulness and manifold applicability in all galvanic experiments, served to effect an easy and certain combination of the wires with the plates; the first, it is true, has long been known to some experimentalists. They are both represented of the actual size in the annexed Fig. 2. The first 
Fig. 2.

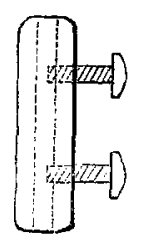

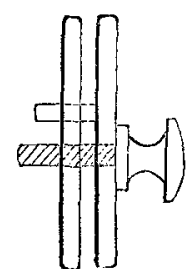

consists of a bored copper cylinder with two side screws. In this is inserted from the one side the end of the connecting wire, and from the other the piece of wire soldered to the plate, or instead of that the plate itself, which can be so cut that it may be inserted in it. When the screws are tightened connexion is made. The second is constructed of two copper plates, which can be pressed against one another by a screw. In order that this may be effected without disturbing the plates, the one is provided with a pin which fits into an aperture in the other; this latter has also in the centre, on its inner side, a wedge-shaped furrow for its whole length. By means of this second clamp, thin plates, to which it is not desirable to solder pieces of wire, may be, as will easily be conceived, combined with wires, for the better insertion of which the above-mentioned furrow is made. The two clamps in this respect serve perfectly well all the purposes of mercury, without possessing its numerous inconveniences.

In general the current of a circuit of the kind described has but slight intensity; nevertheless it is always very perceptible with a sensitive multiplier. Frequently it was even so energetic that the magnetic needle of the instrument beat with violence against the pins which were erected at the points $90^{\circ}$ to prevent its entire reversion; but often the deflections were but feeble, and in these cases especially 1 always took the precaution to exchange reciprocally the four plates employed for each experiment, and to take the mean from all the readings. In this way, it is true, each experiment became four experiments; but this exchange is quite necessary, as we never find, especially in plates of nonnoble metals, iron and zinc, two homogeneous to such a degree, even when cut out of the same mass, as not to produce, when immersed alone in a conducting fluid, a frequently considerable current, which might easily overpower that which is intended to be observed.

Only in some cases where $I$ was already acquainted with the direction of the current, for instance on repeating some experiments which I had previously performed, was I satisfied with employing the zinc plates in the combination, so that their heterogeneity should act against the current, !instead of exchanging them. If the current was merely weakened by this, and not reversed, the result can be noted as certain.

I had hoped that the heterogeneity of the zinc would be less with the distilled metal, but found it nearly quite as great as with the common zinc, and even, as with the latter, increasing 
on long use in acids, so that plates which fresh were nearly homogeneous, acquired with time a considerable heterogeneity. Filing the surfaces thoroughly bright was the sole means of restoring them to their original state. Nevertheless I employed in the further progress of my inquiries, and on the repetition of experiments, only distilled zinc, to be more certain.

For a similar reason $I$ also had recourse to amalgamated zinc. Plates of ordinary zinc, possessing a very considerable degree of heterogeneity, lose it in fact by amalgamation (produced by rubbing them with dilute sulphuric acid and nercury), and become almost perfectly homogeneous; but they remain so only immediately after this operation, so long as the surface of the metal is, as it were, fluid. After some time the amalgam hardens to a crystalline mass, generally sooner or to a greater extent on one plate than on the other, and then the heterogeneity again makes its appearance. The plate with the fluid surface is in acids positive to that with the crystalline dull appearance. By rubbing the latter with mercury the heterogeneity may again be suppressed. Although it is in our power to bring amalgamated zinc plates to any degree of homogeneity previous to each experiment, yet it did not appear advisable to employ solely such, as amalgamated zinc must in a certain degree be regarded as a different metal from ordinary zinc, and its easy liability to change might produce disturbances. The sequence, however, showed that in general it affords the same results as the non-amalgamated zinc, and in numerous cases possesses considerable advantages over the latter.

Besides this, no precaution was neglected that is indispensable in this kind of experiments*; for instance, the cleansing of the plates after each experiment, by immersion in water,

* Here among other things might be reckoned the order of immersion, for it is a well-known fact, that of two plates of one and the same metal, on being immersed in a like fluid, that dipped in last is always negative to the one first inserted. I have found this to be perfectly true, but have likewise observed that on the contemporaneous immersion of two zinc plates in water slightly acidulated with sulphuric acid, several reversions in the direction of the current are produced; for instance, in the first moment a westerly deflection of $10^{\circ}$, followed by an easterly of $70^{\circ}$, which was soon succeeded by a permanent easterly deflection of $20^{\circ}$, that gradually sunk down to $0^{\circ}$, and passed into a westerly deflection of $38^{\circ}$; sometimes a couple more reversions occurred. After several contemporaneous takings out and immersions only the westerly deflection was evident. A mere knocking one of the plates against the bottom of the vessel, which produced an elevation of about $\frac{1}{2}$ line, rendered this plate negative, or, causing with respect to the deflection, an increase or diminution in this deflection, although but transitory. The plates employed for this purpose were recently scoured, and at the termination of the experiments, which lasted nearly an hour, they had lost from the weakness of the acid little or nothing of their brightness. Both became covered with bubbles of hydro- 
drying with bibulous paper, or, if it seemed requisite, by rubbing with sand-paper, scouring with sand and acids or water; although these operations are exceedingly troublesome from frequent repetition, yet they were never neglected. Moreover, the platina was, previous to each experiment, heated over an alcohol lamp after having been cleansed, as it otherwise only produces weak effects. I therefore believe that the following results merit some confidence, especially as most of them are deduced from several experiments repeated on various days.

Before, however, communicating these results, I must still add one remark.

By whatever cause the electricity may be produced in circuits of this kind, it is evident that there can be no doubt respecting the where, that it can only occur at the places of contact of the fluids with the metals,-since a contact of heterogeneous metals does not take place, or rather each of the two metallic slips contains two such contacts, which, from their being of opposite nature, must necessarily nullify each other. There are, therefore, in this kind of circuits four possible places of excitation, two in each vessel; and if we combine the electromotive force developed in each vessel, we have two such forces, $e$ and $e^{\prime}$, which act in opposition to each other. If, moreover, we call $r$ the total resistance of the circuit, then, according to Ohm's fundamental law for the intensity of the resulting current, we obtain the expression $\frac{e-e^{\prime}}{\dot{r}}$.

Accordingly, the direction of the current, i.e. the direction of the deflection of the needle of the multiplier, depends solely on the sign of the difference $e-e^{\prime}$; on the other hand, the intensity of the current, or the magnitude of the deflection, both on the value of the difference $e-e^{l}$ and on the value $r$ of the resistance. The amount of the deflection of the needle affords

gen, the temporarily negative one, so it seemed, always to a greater extent; yet but few bubbles ascended from it.

Amalgamated plates exhibit the same phænomena; but since in this case stronger acid may be employed without giving rise to any disturbance, it can be observed that the mere raising one of the plates about one inch renders it considerably negative; re-immersion again increases the negativeness. I observed this with sulphuric acid of 1.827 spec. gx. diluted with 9 times its volume of water, into which the plates were immersed to the depth of $2.5 \mathrm{inch}$.

These enigmatical currents are all of them, however, but of transitory duration, and they can therefore, in the following experiments, in which the positive metal, situated in the acid, was in most cases immersed last, at the utmost have only effected the first deflections, and then only when these were feeble. But in general the heterogeneity which originates for the positive plates from the contact with two fiuids, is far stronger. At times I have also convinced myself that the results were essentially the same, whether the positive plates were immersed at the same time, or one after the other, before or after the negative plates. 
alone, therefore, no measure for the difference of the electromotive forces here entering into action, the determination of which, however, is the sole object of the present inquiry. I have therefore, in the following experiments, chiefly directed my attention to the accurate determination of the direction of the current; its relative intensity, being dependent on too many circumstances, is only given approximately: the magnitude of the deflections of the needle were, however, always carefully noted.

M. Vorsselman de Heer, in his valuable memoir on Electric Telegraphy*, states of this numerator, after having observed that it depends on the nature of the metals, and not on their dimensions ; that its value is not altered when salts, alkalies, or acids, which, like sulphuric acid, or nitric acid, are not electrolyzable, are added to the water; but that it undergoes a change when the body which is added is itself an electrolyte, for instance hydrochloric acid, in which case the numerator would be smaller.

According to Faraday, who, however, is not acquainted with Ohm's theory, this numerator would be greater, the stronger the affinity of the positive metal, the zinc, is for the oxygen, chlorine, or electro-negative constituent of the fluid in general; it must, however, be here observed, that we possess at present nothing more than approximate valuations from which we may judge of the energy of a chemical affinity.

The main result of my experiments has proved in the most positive manner that the value of the numerator in Ohm's formula, or the magnitude of the electromotive force in general is altered, sometimes increased, sometimes diminished, by any substance added to the water, be it an electrolyte or not, and indeed (which should be well observed) increased for one metal combination, and diminished for another, by the same substance, added to the water in the same proportion.

Nor have I been able to find that this force stands in direct ratio to the energy of the affinity between the positive metal and the negative constituent of the fluid. It is weak in cases where this energy must be considered as strong, and on the contrary strong where but a weak affinity can be admitted. Frequently, indeed, a current originates, and at times a powerful one, where, to judge from the affinity, not the slightest action should be expected.

Sufficient proofs of this will be found in the statements contained in the following Tables.

To render these Tables intelligible, it may be observed that

* Poggendorff"s Annalen, vol, xlvi. p. 516. 
the signs of inequality express which of the two fluids ( $a$ and $b$, fig. 1, page 489) developes the strongest electromotive force when a pair of plates of the metals stated at the head of the column are immersed in them. The expression $s<w$, for instance, in the space common to the columns zinc-silver, and hydrochloric acid water, indicates that in contact with zinc and silver the water excites a greater electromotive force than the hydrochloric acid; or, in othęr words, that the current has a direction as if the zinc plate in the water were positive to the zinc plate immersed in the acid, the word positive being taken in the sense previously mentioned.

I might also have added to the direction of the current, or the direction of the magnetic deflections, their magnitudes, as I always noted them carefully. But I have omitted this, on the one hand, because the intensity of the current is no measure of the difference of the electromotive forces under consideration, and also because in the present case it is at the same time a very variable element. In general the intensity of the current in this kind of circuits is most powerful in the first moment, and then rapidly decreases; the amount and velocity of the decrease vary however considerably. This causes among other things that in two cases the difference of the two first deflections of the needle, to the right and to the left, may indeed be equal, but the magnitudes of the deflections differ considerably. In the one case these deflections amounted perhaps to $10^{\circ}$ and $8^{\circ}$, in the other to $30^{\circ}$ and $28^{\circ}$. In general the intensity of the current only descends to zero, but at times it also increases towards the opposite side. Sometimes this reversion of the current takes place so rapidly, that, for example, the first deflection of the needle, perhaps of $50^{\circ}$ to the right, is immediately succeeded by one on the left of $70^{\circ}$. Now and then the intensity of the current is but feeble in the first moment, increases then for a time, and then gradually sinks to zero. Such variations render a numerical comparison of the intensity of the current in the different cases quite impossible, especially as in general, on the repetition of one and the same experiment, highly different values are obtained for the magnitudes of the deflections. I have therefore merely stated in general, in the notes to the Table, when the current was especially strong or feeble: when reversions of the current result, they are for the most part already indicated in the Table by the signs of inequality placed beneath one another. 


\section{DIFFERENCE OF THE ELECTROMOTIVE FORCES ON THE CON-} TACT OF TWO METALS WITH TWO FLUIDS.

\begin{tabular}{|c|c|c|c|c|c|}
\hline No. & $\begin{array}{l}\text { Fluids of the degrees of concen- } \\
\text { tration mentioned. }\end{array}$ & $\begin{array}{l}\text { Zinc. } \\
\text { Platina. }\end{array}$ & $\begin{array}{r}\text { Zinc. } \\
\text { Silver. }\end{array}$ & $\begin{array}{c}\text { Zinc. } \\
\text { Copper. }\end{array}$ & $\begin{array}{l}\text { Zinc. } \\
\text { Tin. }\end{array}$ \\
\hline 1 & $\begin{array}{l}\text { Sulphuric acid }(s) \\
\text { Water }(w)\end{array}$ & $\begin{array}{l}s>w \\
s<w\end{array}$ & $s<w$ & $s<w$ & $s<w$ \\
\hline 2 & $\begin{array}{l}\text { Nitric acid }(s) \\
\text { Water }(w)\end{array}$ & $s>w$ & $s<w$ & $s<w$ & $s=w$ \\
\hline 3 & $\begin{array}{l}\text { Hydrochloric acid }(s) \\
\text { Water }(w)\end{array}$ & $s<w$ & $s<w$ & $s<w$ & $s<w$ \\
\hline 4 & $\begin{array}{l}\text { Solution of chlorine }(c) \\
\text { Water }(w)\end{array}$ & $c>w$ & $c<w$ & $c<w$ & $c=w$ \\
\hline 5 & $\begin{array}{l}\text { Solution of chlorine }(c) \\
\text { Hydrochloric acid }(w)\end{array}$ & $c>s$ & $c>s$ & $c>s$ & $\begin{array}{l}c<s \\
c>s\end{array}$ \\
\hline 6 & $\begin{array}{l}\text { Caustic potash }(a) \\
\text { Water }(w)\end{array}$ & $a>w$ & $a>w$ & $a>w$ & $a<w$ \\
\hline 7 & $\begin{array}{l}\text { Ammonia }(a) \\
\text { Water }(w)\end{array}$ & $a>w$ & $a>w$ & $a<w$ & $a>w$ \\
\hline 8 & $\begin{array}{l}\text { Carbonate of soda }(n) \\
\text { Water }(w)\end{array}$ & $n<w$ & $n<w$ & $n<w$ & $n<w$ \\
\hline 9 & $\begin{array}{l}\text { Sulphuric acid }(s) \\
\text { Borax }(b)\end{array}$ & $s>b$ & $s>b$ & $s>b$ & $s>b$ \\
\hline 10 & $\begin{array}{l}\text { Sulphuric acid }(s) \\
\text { Iodide of potassium }(i)\end{array}$ & $s<i$ & $s>i$ & $s>i$ & $s<i$ \\
\hline 11 & $\begin{array}{l}\text { Hydrochloric acid }(s) \\
\text { Iodide of potassium }(i)\end{array}$ & $s<i$ & $s>i$ & $s>i$ & $s<i$ \\
\hline 12 & $\begin{array}{l}\text { Sulphuric acid }(s) \\
\text { Sal-ammoniac }(l)\end{array}$ & $s<l$ & $s<l$ & $s>l$ & $s<l$ \\
\hline
\end{tabular}

1. With platina $s>w$ merely weak, already diminishing on the second immersion, and then $s<w$ stronger than with silver, copper, tin; with tin $s<w$ increasing.

2. Results differing with silver, sometimes $s=w$, sometimes $s>w$, in most cases however decidedly $s<w$.

3. All action feeble; with copper however pretty strong.

4. With platina and copper very strong, somewhat weaker with silver. With $t$ in an inclination to $c<w$.

5. With platina and copper very strong, with silver weaker, with tin only the first (strong) deflection $c<s$, immediately succeeded by strong $c>s$.

6 . With silver $a>w$ strong, after which, though to a slighter extent, with tin the $a<w$.

7. Strongest effects with silver and copper.

8. Action feeble, strongest with platina and copper.

9. Action pretty strong, weakest with silver.

10. With platina in two experiments, first $s>i$ very strong, which however rapidly decreased and changed into $s<i$ quite as powerful. In all the following experiments, although the platina was always previously heated, the first effect was $s<i$ and generally very strong, sometimes moderate at the commencement, and on repeated immersion increasing.-With silver and copper action very strong, with tin likewise but opposite.

11. With non-heated platina, sometimes, but very feeble, $s>i$, passing into $s<i$. But with heated platina immediately and very strong $s<i$. With silver and copper $s>i$ very strong, with $\operatorname{tin} s<i$ moderate.

12. With copper the $s>l$ strong, still stronger $8<l$ with $t i n$. With a circuit of $t$ in and copper likewise $s>l$. 


\begin{tabular}{|c|c|c|c|c|c|}
\hline No. & $\begin{array}{l}\text { Fluids of the degrees of concen- } \\
\text { tration mentioned. }\end{array}$ & $\begin{array}{c}\text { Zine. } \\
\text { Platina. }\end{array}$ & $\begin{array}{l}\text { Zinc. } \\
\text { Silver. }\end{array}$ & $\begin{array}{l}\text { Zinc. } \\
\text { Copper. }\end{array}$ & $\begin{array}{l}\text { Zinc. } \\
\text { Tin. }\end{array}$ \\
\hline 13 & $\begin{array}{l}\text { Hydrochloric acid }(s) \\
\text { Sal-ammoniac }(l)\end{array}$ & $\begin{array}{l}s>l \\
s<l\end{array}$ & $s<l$ & $s<l$ & $s<l$ \\
\hline 14 & $\begin{array}{l}\text { Salt }(k) \\
\text { Water }(w)\end{array}$ & $\begin{array}{l}k>w \\
k<w\end{array}$ & $k<w$ & $k<w$ & $k=w$ \\
\hline 15 & $\begin{array}{l}\text { Salt }(k) \\
\text { Hydrochloric acid }(s)\end{array}$ & $\begin{array}{l}k<s \\
k>s\end{array}$ & $k>s$ & $k>s$ & $k>s$ \\
\hline 16 & $\begin{array}{l}\text { Salt }(k) \\
\text { Sal-ammoniac }(l)\end{array}$ & $k<l$ & $k<l$ & $k<l$ & $k<l$ \\
\hline 17 & $\begin{array}{l}\text { Sulphate of zinc }(z) \\
\text { Borax }(b)\end{array}$ & $z>b$ & $z>b$ & $z>b$ & $z>b$ \\
\hline 18 & $\begin{array}{l}\text { Sulphate of magnesia }(m) \\
\text { Borax }(b)\end{array}$ & $m>b$ & $m>b$ & $m>b$ & $m>b$ \\
\hline
\end{tabular}

\begin{tabular}{|c|c|c|c|c|c|}
\hline No. & $\begin{array}{l}\text { Fluids of the degrees of concen- } \\
\text { tration mentioned. }\end{array}$ & $\begin{array}{l}\text { Iron. } \\
\text { Platina. }\end{array}$ & $\begin{array}{l}\text { Iron. } \\
\text { Silver. }\end{array}$ & \begin{tabular}{|c|} 
Iron. \\
Copper.
\end{tabular} & $\begin{array}{l}\text { Iron. } \\
\text { Tin. }\end{array}$ \\
\hline 19 & $\begin{array}{l}\text { Sulphuric acid }(s) \\
\text { Water }(w)\end{array}$ & $\begin{array}{l}s>w \\
s<w\end{array}$ & $s=w$ & $s<w$ & $s<w$ \\
\hline 20 & $\begin{array}{l}\text { Hydrochloric acid }(s) \\
\text { Water }(w)\end{array}$ & $s<w$ & $s<w$ & $s<w$ & $s<w$ \\
\hline 21 & $\begin{array}{l}\text { Caustic potash }(a) \\
\text { Water }(w)\end{array}$ & $a<w$ & $a<w$ & $a<w$ & $a<w$ \\
\hline 22 & $\begin{array}{l}\text { Ammonia }(a) \\
\text { Water }(w)\end{array}$ & $a<w$ & $a<w$ & $a<w$ & $a<w$ \\
\hline 23 & $\begin{array}{l}\text { Sulphuric acid ( }(s) \\
\text { Iodide of potassium ( } i \text { ) }\end{array}$ & $s>i$ & $s>i$ & $s>i$ & $s<i$ \\
\hline 24 & $\begin{array}{l}\text { Hydrochloric acid (s) } \\
\text { Iodide of potassium (i) }\end{array}$ & $\begin{array}{l}s>i \\
s<i\end{array}$ & $s>i$ & $s>i$ & $s<i$ \\
\hline 25 & $\begin{array}{l}\text { Sulphuric acid }(\varepsilon) \\
\text { Borax }(b)\end{array}$ & $s>b$ & $s>b$ & $s>b$ & $s>b$ \\
\hline 26 & $\begin{array}{l}\text { Sulphuric acid (s) } \\
\text { Sulphate of zinc }(z)\end{array}$ & $s<z$ & $s<z$ & $s<z$ & $s<z$ \\
\hline
\end{tabular}

13. With platina at first $s>l$ slowly passing over into a stronger $s<l$. Silver weak, copper strong (although of opposite nature as with sulphuric acid), tin very strong.

14. Platina weak, silver and tin moderate, copper strong.

15. Silver weak, the other metals moderate.

16. Copper strong, platina almost nil.

17. Platina and copper pretty strong.

18. Copper strongest.

19. All actions feeble.

20. Likewise: with copper strongest.

21. Platina moderate, silver weak, copper pretty strong, tin very strong.

22. Silver weak, tin moderate, platina pretty strong, copper very strong.

23. Platina strong, silver and copper very strong, tin feeble.

24. With platina $s>i$ at first and slowly passing into $s<i$ only once observed; subsequently always immediately $s<i$. With silver and copper $s>i$ very strong.

25. With copper and tin strong.

26. With platina strong, after which tin. 


\begin{tabular}{|c|c|c|c|c|}
\hline No. & $\begin{array}{l}\text { Fluids of the degrees of concen- } \\
\text { tration mentioned. }\end{array}$ & $\begin{array}{c}\text { Tin. } \\
\text { Platina. }\end{array}$ & $\begin{array}{l}\text { Tin. } \\
\text { Silver. }\end{array}$ & $\begin{array}{c}\text { Tin. } \\
\text { Copper. }\end{array}$ \\
\hline 27 & $\begin{array}{l}\text { Sulphuric acid }(s) \\
\text { Water }(w)\end{array}$ & $s<w$ & $s>w$ & $s>w$ \\
\hline 28 & $\begin{array}{l}\text { Nitric acid }(s) \\
\text { Water }(w)\end{array}$ & $s<w$ & $s<w$ & $s<w$ \\
\hline 29 & $\begin{array}{l}\text { Hydrochloric acid }(s) \\
\text { Water }(w)\end{array}$ & $s<w$ & $s<w$ & $s<w$ \\
\hline 30 & $\begin{array}{l}\text { Caustic potash }(a) \\
\text { Water }(w)\end{array}$ & $\begin{array}{l}a=w \\
a>w\end{array}$ & $a>w$ & $a>w$ \\
\hline 31 & $\begin{array}{l}\text { Ammonia }(a) \\
\text { Water }(w)\end{array}$ & $a<w$ & $a<w$ & $a<w$ \\
\hline 32 & $\begin{array}{l}\text { Sulphuric acid }(s) \\
\text { Iodide of potassium }(i)\end{array}$ & $s>i$ & $s>i$ & $s>i$ \\
\hline 33 & $\begin{array}{l}\text { Hydrochloric acid }(s) \\
\text { Iodide of potassium }(i)\end{array}$ & $\begin{array}{l}s>i \\
s<i\end{array}$ & $s>i$ & $s>i$ \\
\hline
\end{tabular}

\begin{tabular}{|c|c|c|c|c|c|c|c|}
\hline No. & $\begin{array}{c}\text { Fluids of the degrees of con- } \\
\text { centration mentioned. }\end{array}$ & $\begin{array}{c}\text { Amalg. } \\
\text { of } \\
\text { Zinc. } \\
\text { Platina. }\end{array}$ & $\begin{array}{c}\text { Amalg. } \\
\text { of } \\
\text { Zinc, } \\
\text { Silver. }\end{array}$ & $\begin{array}{l}\text { Amaig. } \\
\text { of } \\
\text { Zinc. } \\
\text { Copper. }\end{array}$ & $\begin{array}{l}\text { Amalg. } \\
\text { of } \\
\text { Zinc. } \\
\text { Tin. }\end{array}$ & $\begin{array}{c}\text { Amalg. } \\
\text { of } \\
\text { Zinc. } \\
\text { Iron. }\end{array}$ & $\begin{array}{l}\text { Amalg. } \\
\text { of Zinc. } \\
\text { distilled } \\
\text { Zinc. }\end{array}$ \\
\hline $\begin{array}{l}34 \\
35 \\
36\end{array}$ & $\begin{array}{l}\text { Sulphuric acid }(s) \\
\text { Water }(w) \\
\text { Hydrochloric acid }(s) \\
\text { Water }(w) \\
\text { Caustic potash }(a) \\
\text { Water }(w)\end{array}$ & $\begin{array}{l}s>w \\
s<w \\
s>w \\
s<w \\
a>w\end{array}$ & $\begin{array}{l}s<w \\
s<w \\
a>w\end{array} \mid$ & $\begin{array}{l}s<w \\
s<w \\
a>w\end{array}$ & $\begin{array}{l}s<w \\
s>w \\
a<w\end{array}$ & $\begin{array}{l}s>w \\
s>w \\
s>w \\
s>w \\
a>w\end{array}$ & $\begin{array}{l}s<w \\
s>w \\
s<w \\
s>w \\
a<w \\
a>w\end{array}$ \\
\hline
\end{tabular}

27. With silver and copper the $s>w$ weak, often $s=w$.

28. All weak, yet with platina the first deflection $=20^{\circ}$.

29. Actions weak, the least so with copper.

30. With silver and copper stronger than with platina.

31. With silver and platina weak, with copper pretty strong.

32. Silver and copper strong, platina very feeble.

33. With platina both the $s>i$ as also the subsequent $s<i$ weak. With silver and copper the $s>i$ very strong.

34. In all the experiments with amalgamated zinc plates these were constantly kept in the fluids, and the negative plates only were taken out and immersed both at the same time. - With platina only the first deflection of $10^{\circ}$ to $20^{\circ}$ in the direction $s>w$, succeeded by one of $90^{\circ}$ in the direction of $s<w$. The effect far more energetic than with silver, copper, tin, and than with distilled, not amalgamated, zine in similar experiments (although here as well as in No. 1 the platina had been heated to redness). - With iron immediately a very slow deflection of $20^{\circ}$ to $30^{\circ}$, then a tranquil increase of the deffection to a permarient value of $40^{\circ}$ and above. - With zinc immediately $70^{\circ}$ in the direction $s<w$, rapidly decreasing and passing into $s>w$ to $20^{\circ}$.

35. In this case with platina the reversion evident, but making its appearance slowly ; after repeated immersions only $s<w$. - Tin forming an exception from No. 3, 20, 29.-With iron no increasing effect as in No. 34, but giving a stronger one than there.-Zinc as in No. 34.

36. With platina weak, with copper somewhat stronger, but very strong with silver and iron. The $a<w$ with tin pretty powerful ; both effects weak with $z i n c$.

$$
\text { Phil. Mag. S. 3. Vol, 16. No. 105, June 1840, } 2 \mathrm{~L}
$$




\begin{tabular}{|c|c|c|c|c|c|c|c|}
\hline No. & $\begin{array}{l}\text { Fluids of the degrees of con- } \\
\text { centration mentioned. }\end{array}$ & $\begin{array}{c}\text { Amalg. } \\
\text { of } \\
\text { Zinc. } \\
\text { Platina. }\end{array}$ & $\begin{array}{l}\text { Amalg. } \\
\text { of } \\
\text { Zinc. } \\
\text { Silver. }\end{array}$ & $\begin{array}{l}\text { Amalg. } \\
\text { of } \\
\text { Zinc. } \\
\text { Copper. }\end{array}$ & $\mid \begin{array}{c}\text { Amalg. } \\
\text { of } \\
\text { Zinc. } \\
\text { Tin. }\end{array}$ & $\begin{array}{c}\text { Amalg. } \\
\text { of } \\
\text { Zinc. } \\
\text { Iron. }\end{array}$ & $\begin{array}{l}\text { Amalg. } \\
\text { of Zinc, } \\
\text { distilled } \\
\text { Zinc. }\end{array}$ \\
\hline 38 & $\begin{array}{l}\text { Ammonia }(a) \\
\text { Water }(w) \\
\text { Sulphuric acid }(s) \\
\text { Iodide of potassium }(i) \\
\text { Hydrochloric acid }(s) \\
\text { Iodide of potassium }(i)\end{array}$ & $\begin{array}{l}a>w ? \\
s<i \\
s<i\end{array}$ & $\begin{array}{l}a>w \\
s>i \\
s>i\end{array}$ & $\begin{array}{l}a<w \\
s>i \\
s>i\end{array}$ & $\begin{array}{l}a>w \\
s<i \\
s>i \\
s<i\end{array} \mid$ & $\begin{array}{l}a>w \\
s<i \\
s>i \\
s<i \\
s>i\end{array}$ & $\begin{array}{l}a>w \\
s<i \\
s>i \\
s<i \\
s>i\end{array}$ \\
\hline
\end{tabular}

37. With platina, copper, and zinc feeble, stronger with silver, still stronger with $t i n$, and exceedingly strong with iron.

38. Even with non-heated platina the $s<i$ powerful. The $s>i$ also strong with silver and copper, less so the $s<i$ with $t i n$. With iron the action exceedingly energetic, first a deflection of $40^{\circ}$ in the direction $s<i$, immediately succeeded by one of $90^{\circ}$ and oscillations between $90^{\circ}$ and $80^{\circ}$ in the direction $s>i$.-With zinc just the same, the first deflection in the direction $s<i=90^{\circ}$, the second in the direction $s>i=90^{\circ}$ followed by oscillations between +90 and $+75^{\circ}$.

39. Even with non-heated platina $s<i$ powerful, with it at least no reversion. With silver and copper action very strong.-With tin the $s>i$ weak, slowly, and especially after repeated immersion passing into $s<i$. W With iron only the first deflection of $60^{\circ}$ to $70^{\circ}$ in the direction $s<i$, the second immediately in the direction $s>i=90^{\circ}$, then oscillations from $+90^{\circ}$ to $+80^{\circ}$. With zinc precisely the same.

A careful glance at the facts contained in these Tables will justify the correctness of the positions above advanced. I will here draw attention to some distinct cases which will establish them more perfectly.

[To be continued.]

LXXV. On the moving the Knight over every Square of the Chess-board alternately. By George Walker, Author of various Works on Chess; and Honorary Secretary of the St. George's Chess Club.

\section{To the Editors of the Philosophical Magazine and Journal.}

\section{Gentlemen,}

YOUR Number for the present month has just come into my hands, and I find it contains an interesting paper upon the knight's move, by Dr. Roget, to which my attention is particularly drawn, from the circumstance of that essay having, it appears, been suggested by one of my chess articles in Fraser's Magazine (see Fraser of March 1840.). In that memoir, the subject of the knight's circuitous leap was merely touched upon en 